Canadian

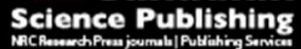

Canadian Journal of Forest Research Revue canadienne de recherche forestière

\title{
Natural tree regeneration and vegetation dynamics across harvest gaps in Norway spruce-dominated forests in Southern Finland.
}

\begin{tabular}{|r|l|}
\hline Journal: & Canadian Journal of Forest Research \\
\hline Manuscript ID & cjfr-2017-0358.R2 \\
\hline Danuscript Type: & Article \\
\hline Complete List of Authors: & $\begin{array}{l}\text { Downey, Margot; N/A } \\
\text { Valkonen, Sauli; Natural Resources Institute Finland (Luke), } \\
\text { Heikkinen, Juha; Natural Resources Institute Finland, Economics and } \\
\text { society }\end{array}$ \\
\hline $\begin{array}{r}\text { Keyword: } \\
\text { Ko the invited manuscript for } \\
\text { consideration in a Special } \\
\text { Issue? : }\end{array}$ & N/A \\
\hline &
\end{tabular}

SCHOLARONE ${ }^{\text {M }}$

Manuscripts 
1 Natural tree regeneration and vegetation dynamics across harvest gaps in Norway spruce dominated forests in Southern Finland

5 List of authors:

6 Margot Downey ${ }^{1)}$, e-mail: downey_m@hotmail.com

7 Sauli Valkonen ${ }^{2)}$, e-mail: sauli.valkonen@luke.fi

8 Juha Heikkinen ${ }^{2)}$, e-mail: juha.heikkinen@luke.fi

11 For 1), Affiliation: Department of Forest Sciences, University of Helsinki

12 Address: PO Box 27, FI-00014 Helsinki, Finland

13

14 For 2), Affiliation: Natural Resources Institute Finland (Luke)

15 Address: PO Box 2, FI-00791 Helsinki, Finland

16

17

18 Corresponding author:

19 Name: Margot Downey

20 Address: 69 Huron Ave. N., Ottawa, Ontario, K1Y 0W1, Canada

21 Tel.: +1-514-814-3775

22 e-mail: downey_m@hotmail.com 


\section{Abstract}

24 We analysed the impact of forest gap characteristics and understory vegetation on the natural

25 regeneration patterns of Norway spruce and birch. The gaps were located in spruce-dominated

26 forests in Southern Finland, and had been established by harvesting 4-5 growing seasons earlier.

27 Their diameters ranged from $30-60 \mathrm{~m}$. In order to analyze the complex patterns of multiple

28 factors simultaneously, we analysed the data using generalized additive models. The models

29 included gradients related to distance from gap (forest) edge, cardinal position in the gap,

30 understory vegetation, microsite types and microtopography. The high number of seedlings

31 inside the gaps suggests promising regeneration potential-some 20.3 spruce and 6.8 birch

32 seedlings per $\mathrm{m}^{2}$. The $0-15 \mathrm{~m}$ zone into the gap supported the greatest seedling abundance. Gap

33 centers $(15 \mathrm{~m}+)$ fostered a highly competitive environment, and hosted much lower seedling

34 densities. Northern gap positions varied most significantly, supporting fewer birch seedlings, and

35 greater covers of grasses and dwarf shrubs. The results indicate that harvested forest gaps should

36 have diameters less than 40m (at least initially) in order to prevent excessive proliferation of

37 understory vegetation and to facilitate seedling emergence across the gaps under similar

38 conditions.

40 Key words: Natural regeneration, boreal forest, understory vegetation, gap, microsite 


\section{Introduction}

42 Gap harvesting is among the main harvesting methods employed in uneven-aged forest

43 management of Norway spruce (Picea abies (L.) Karst.)-dominated stands in the Nordic region.

44 This method, and uneven-aged forest management as a whole, is quite novel in the region, and as

45 such very little experience and research-based knowledge is available for practitioners and

46 scientists. Forest gaps tend to promote natural tree regeneration by establishing environmental

47 conditions suitable for the recruitment, survival and growth of tree seedlings (Liu and Hytteborn

48 1991, Kuuluvainen 1994). The factors influencing tree regeneration are related to the newly

49 established gradients across the gap in terms of light, temperature, moisture, competition from

50 trees in the gap edge zone, and seed crops. Variations in light, moisture and temperature across

51 the gap are largely controlled by variations in incoming solar radiation. The patterns of solar

52 radiation vary according to the cardinal position in the gap $(\mathrm{N}, \mathrm{S}, \mathrm{E}$, or $\mathrm{W})$, with the greatest

53 levels of radiation occurring at the northern-central gap positions (Canham et al. 1990, Raymond

54 et al. 2006). Within northern latitudes, this effect also extends into the residual stand, where

55 radiation levels can be as high as $50 \%$ of the incoming radiation in the northern gap edge

56 positions (De Chantal et al. 2003). Forest gaps also include a large range of microsite types (e.g.

57 bare mineral soil, stumps), all of which play a central role in the success of tree seedling

58 establishment and growth (Zasada et al. 1992, Kuuluvainen 1994, Hanssen 2002, 2003). These

59 microsite conditions affect regeneration in variable ways, and the effects often vary among tree

60 species (Grenfell et al. 2011).

61 These environmental gradients also greatly influence the patterns of understory vegetation

62 composition across the gap. Understory vegetation can play a critical role especially in early

63 post-harvest tree regeneration dynamics, since as a whole understory vegetation is able to 
64 respond quite rapidly (3-5 years) to the new post-harvest conditions (Hill et al. 2005, Stewart

65 and Mallik 2006, Vanha-Majamaa et al. 2017). Species groups that increase in cover after

66 harvesting include shrubs, grasses and sedges, and early successional light-demanding herb

67 species (Grushecky and Fajvan 1999, Domke et al. 2007). Understory vegetation is also very

68 sensitive to variations in microsite conditions, topography and resource availability, and the

69 patterns of plant species regeneration reflect this (Palmer and Dixon 1990, Tonteri 1994, Halpern

70 et al. 2005). As a result, vegetation species composition usually displays quite variable spatio-

71 temporal dynamics and compositional patterns. As natural regeneration progresses, the

72 intensifying competition from understory vegetation and other seedlings also greatly affect the

73 patterns of tree regeneration (e.g., Kuuluvainen 1994, Huggard and Vyse 2002, Hanssen 2003,

74 Valkonen et al. 2011). Consequently, understory vegetation can be an important tool for

75 revealing the finer-scale nuances of gap-level heterogeneity, and can help to better understand

76 the processes affecting seedling regeneration across gaps.

77 Previous studies have often focused only on the most obvious factors affecting tree regeneration

78 in gaps (Valkonen et al. 2011, Valkonen and Siitonen 2016). When specifically targeted, the

79 effects of the factors controlling regeneration have been researched either individually, or in

80 conjunction with only a small number of factors (e.g. De Chantal et al. 2003, Hanssen 2003).

81 Given their complexity and interrelated nature, it is critical to study multiple factors

82 simultaneously to parse out which are most important within the particular regeneration context.

83 Therefore, our approach was to analyze their combined and relative effects within a same model-

84 based framework. Moreover, we examine the effects of various factors on regeneration by spatial

85 gradients, i.e. each observation point's relative distance to the gap edge, paired with each gap's

86 surrounding stand density to quantify the intensity of the competition-related components of 
87 these gradients. Working with spatial distance-based gradients rather than gap sizes (e.g., large

88 vs. small) enables users to apply the knowledge gained about the factors themselves for

89 subsequent interpolation in terms of gap size.

90 The objectives of this study were to:

91 - simultaneously assess the effects of various gap characteristics and patterns of understory

92 vegetation on the natural regeneration dynamics of Norway spruce (Picea abies (L.)

93 Karst.) and birch species (Betula pendula Roth., Betula pubescens Ehrh.) 4-5 growing

$94 \quad$ seasons post-harvest across harvested gaps;

95 - outline the most significant factors affecting the success of early regeneration for Norway

$96 \quad$ spruce and birch;

97 - point to management actions which could facilitate natural tree regeneration in forest

98 gaps under comparable conditions.

99 


\section{Materials and methods}

101 Study area

102 This research was carried out in the Isojärvi experimental forest area in Southern Finland, which

103 has been designated for research and development purposes under the DISTDYN project

104 (Koivula et al. 2014). The experimental area is situated near the town of Jämsä at $61^{\circ} 40^{`} \mathrm{~N}$,

$10525^{\circ} 00^{\prime} \mathrm{E}$, and covers an area of $689 \mathrm{ha}$. It is managed according to the principles of Natural

106 Disturbance Emulation (Attiwill 1994, Bergeron et al. 2002, Long 2009); please see

107 Kuuluvainen and Aakala (2011) for typical natural forest dynamics in this region, and Koivula et

108 al. (2014) for their application in the DISTDYN project.

109 Four different harvesting treatments are applied in the DISTDYN forests, of which "gap felling"

110 and "partial felling" were relevant for this study. They involve harvesting small irregular clearcut

111 gaps with areas of ca. $0.1-0.5$ hectares and diameters of approximately $10-60 \mathrm{~m}$ with $10-50 \mathrm{~m}$

112 wide unharvested (residual) forest buffers in between (Fig. 1). In the Isojärvi experimental forest

113 area, gap and partial felling was carried out in 40 stands during January and February of 2010

114 and 2011. Stand areas vary between 0.5 and 8.9 hectares and each harvested stand contains $1-7$

115 gaps (making up 20-33\% of the total stand area), depending on the availability of stand area,

116 establishing a total of 86 gaps. The first harvesting round at Isojärvi failed to produce the very

117 smallest gap sizes prescribed in terms of "gap felling", and the final diameter range was 30-60m

118 (vs. the intended range of 10-60m). As a result, the two treatment types produced rather similar

119 harvesting results and were therefore merged and referred to as "gaps" in this study. Due to the

120 winter conditions with almost constant subzero air temperatures and abundant snow cover

121 present throughout, soil disturbance from harvesting was minimal. 
122 The predominant forest site types in the Isojärvi area are the submesic Myrtillus type and the

123 mesic Oxalis-Myrtillus type (Cajander 1909). The dominant tree species are Norway spruce

124 (Picea abies (L.) Karst.) and Scots pine (Pinus sylvestris L.). Mixed species stands also occur,

125 most commonly with silver birch (Betula pendula Roth) and pubescent birch (Betula pubescens

126 Ehrh.), and occasionally with European aspen (Populus tremula L.), rowan (Sorbus aucuparia

127 L.), common alder (Alnus glutinosa L.) and grey alder (Alnus incana Moench). Norway spruce

128 and birch make up the primary commercial species on the mesic and submesic sites at Isojärvi.

129 However, as a legacy of the silvicultural preference for Scots pine until the 1980s, many pine

130 stands are still present today on sites considered too fertile for the species. The current tendency

131 in Finland today is to facilitate the conversion of these stands back to Norway spruce and birch.

132 The understory vegetation is dominated by dwarf shrubs (e.g., Vaccinium myrtillus, and

133 Vaccinium vitis-idaea), herbs, grasses/sedges, ferns, mosses and lichens.

135 Sampling and measurements

136 The data was acquired through measurements across harvested gaps located throughout different

137 forest stands. Forest stands and gaps were chosen for this study according to a number of criteria.

138 This study's stands were selected among the 15 stands where permanent stand development and

139 tree regeneration monitoring plots had been established under DISTDYN (in 2010-2011 after

140 "gap" or "partial" felling, as denoted by Koivula et al. 2014). Within this set of stands, we only

141 included those on MT (Myrtillus type) or OMT (Oxalis-Myrtillus type) sites, leaving out the less

142 fertile stands not suitable for Norway spruce or birch regeneration. Furthermore, we restricted

143 sampling to gaps in the central portions of the stands to avoid external influences. Finally, only

144 gaps not treated with site preparation were included in this study. One or two gaps were sampled 
145 from each of the stands in this subset of suitable gaps. If several gaps met the above-mentioned 146 criteria in a given stand, the gaps to be sampled were selected randomly among the subset. In

147 total, eighteen harvested gaps were selected across thirteen forest stands, ranging in size from

$148 \quad 0.10-0.36$ hectares (mean area of 0.19 ha, median area of $0.18 \mathrm{ha}$ ).

149 Measurements were performed during the late summer of 2014. Baselines were established in 150 each gap, with East-West and North-South orientations (Fig. 2). In gaps with diameters $<40 \mathrm{~m}$,

151 one baseline of each orientation was established, each spanning the whole interior of the gap (as

152 is seen in Fig. 2). In gaps with diameters $>40 \mathrm{~m}$, two baselines of each orientation were

153 established, each extending approximately 20m into the gap interior from the gap edge. The gap

154 edge was defined as the point where the baseline crossed the imaginary line that connected the 155 bases of the two nearest trees, as per Runkle (1981).

156 Centered on the baselines, $1 \mathrm{~m}$ wide sampling strips were established for measuring seedlings,

157 understory vegetation and microsite types (Fig. 2). These were assessed on square plots

158 (quadrats), each measuring $1 \mathrm{~m}^{2}(1 \mathrm{~m} \times 1 \mathrm{~m})$, at $2 \mathrm{~m}$ intervals along the sampling strips. On these

159 measurement plots, all Norway spruce and birch (B. pendula and B. pubescens) seedlings $(\leq 5 \mathrm{~m})$

160 were counted. Each of these seedlings were assessed to determine whether they had emerged

161 before (i.e., advance regeneration), or after the gap harvesting treatment. Recently emerged

162 seedlings ("germinants", less than one growing season old) were counted separately, as a subset

163 of the seedlings which emerged after gap harvesting.

164 On these same plots, understory vegetation and microsite types were assessed by percent cover

165 for several key groups, and the dominant microtopography (flat, mound, depression, slope) was

166 recorded. The percentage covers were visually estimated by classes of $0.1 \%$ increments from $0-$

$1671 \%$, and of $1 \%$ increments $(1 \%, 2 \%, 3 \%$, etc.) above $1 \%$. Understory vegetation was assessed by 
168 species groups, and included: shrubs (e.g., Rubus idaeus, Juniperus communis, Ribes spp.,

169 Lonicera xylosteum, Frangula alnus, Amelanchier spicata, and Salix species-except S. caprea

170 and S. pentandra, which were trees), dwarf shrubs (e.g., Vaccinium myrtillus, $V$. vitis-idaea, $V$.

171 uliginosum, Calluna vulgaris, Empetrum nigrum, Ledum palustre, Andromeda polifolia,

172 Arctostaphylos uva-ursi, and Chamaedaphne calyculata), herbs, grasses/sedges, ferns, mosses

173 and lichens. Microsite type groups included: covered stone (by up to approximately $10 \mathrm{~cm}$ of

174 moss, humus, or soil), bare stone, $\operatorname{logs}$ ( $\geq 7 \mathrm{~cm}$ diameter), bases of standing trees, bases of stumps,

175 decaying stumps or logs, duff (leaves, branches, bark and other organic material, in various

176 stages of early decomposition), slash (woody debris created during harvesting operations), bare

177 mineral soil and bare humus. There were 876 of these plots in total, and therefore 876

178 observations for all seedling, understory vegetation, microtopography, and microsite type

179 variables.

180 Also centered on these baselines, $21 \mathrm{~m}$ wide sampling strips were established for measuring trees

181 (Fig. 2). These strips extended 10m beyond all of the seedling/vegetation/microsite sampling

182 strips into the residual stand. For all standing trees on these sampling strips which were $\geq 5 \mathrm{~m}$ in

183 height, the coordinates and diameter at breast height $(1.3 \mathrm{~m})$ were recorded.

\section{Statistical analyses}

186 Mean values and standard deviations for the number of seedlings per $\mathrm{m}^{2}$ (seedling density) and

187 the percent covers of understory vegetation and microsites by groups were computed at each

188 sampled distance from the gap edge, as well as for each strip orientation and microtopography

189 type. Since the distributions of seedling counts and percent covers were severely non-normal, the 
190 statistical significance of the differences between strip orientations and microtopography types

191 was assessed by the non-parametric Kruskal-Wallis one-way analysis of variance test based on

192 ranks. Where significant differences were found, pairwise comparisons between strip

193 orientations or microtopography types were computed using Tukey's post-hoc test. These

194 analyses were conducted separately for sample plots in the interior of the gaps and for those in

195 the residual stand.

196 Generalized additive models (GAMs; Wood 2006) were developed to describe the relationships

197 between the mean density of seedlings that emerged after harvest and the available explanatory

198 variables. Given the often spatially complex nature of gap environments, the benefit of using

199 GAMs is that they can uncover the non-linear effects of the explanatory variables (e.g., Robinson

200 et al. 2011). In this study, nonparametric response functions were fitted to continuous predictors

201 if the estimated degrees of freedom were greater than one. The number of seedlings per plot

202 (seedling densities) were assumed to follow a negative binomial distribution, with mean values

203 determined by the explanatory variables through the logarithmic link function.

204 The final models were found using backward stepwise regression, starting from the full model

205 with all available explanatory variables (basal area, distance from gap edge, position in the gap,

206 topography, as well as all assessed microsite types and understory vegetation groups). In each

207 step, the current model was compared to all reduced models obtained by dropping one covariate

208 according to the following criteria. In cases where several covariates were insignificant

209 according to the ANOVA tests, the first criterion for selecting the one to eliminate was

210 collinearity with significant covariates. If no statistically significant collinearities were found,

211 then the covariate with the highest p-value was eliminated. This process continued until all

212 covariates included in the model were statistically significant $(\mathrm{p}<0.05)$. Note that pairs of 
213 collinear predictors could thus remain in the final model, if they both were significant even when

214 the other was included. AIC scores were also used as a tool to assess the removal of covariate

215 terms at each step of the modeling process. The reduced model was confirmed as an

216 improvement on the full model if it also produced a lower AIC score by $>2$. This process aimed

217 to produce a final model that included the smallest possible number of covariates while

218 producing the lowest AIC score and the highest possible deviance explained. For birch however,

219 we considered the factor type variable of position in the gap as well as the basal area of the edge

220 stand to be key attributes in this context, and therefore they were retained in the models

221 regardless of their final p-values and AIC scores (producing models with AIC scores higher only

222 by $<2$ ). It should be noted that when basal area was removed from the birch seedling model,

223 dwarf shrubs produced a significant $p$-value. The relative importance of the continuous

224 predictors in the final models was assessed by computing the decrease in 'Deviance explained'

225 resulting from dropping each predictor in turn from the full model (metric 'last' in Grömping

226 2006). All analyses were carried out in the R environment, version 3.1.2 (R Core Team 2014),

227 with package mgcv (Wood 2011) applied for GAM modelling. 


\section{Results}

\section{$230 \quad$ Observed seedling density}

231 The mean seedling density per $\mathrm{m}^{2}$ within the gaps was 20.36 for Norway spruce and 6.82 for

232 birch species. Of the spruces, 62\% were germinants (with an age of one growing season or less),

$23327 \%$ were seedlings that had emerged after harvesting and were older than one growing season,

234 and $11 \%$ were advance regeneration that had existed prior to harvesting. These respective values

235 for birch were $29 \%, 46 \%$, and $25 \%$. In the residual edge forests there were much fewer birch

236 seedlings than inside the gaps (2.4 per $\mathrm{m}^{2}$ on average), but almost as many spruces (19.6 per $\mathrm{m}^{2}$

237 on average). Mean values of the studied variables for all plots combined, i.e. inside the gap and

238 residual forest, are presented in Table 1. The greatest seedling density occurred inside the gaps,

239 in the $5-10 \mathrm{~m}$ zone for Norway spruce and in the $0-10 \mathrm{~m}$ zone for birch species (Fig 3 ). In the

240 central gap positions $(15 \mathrm{~m}+$ from the gap edge towards the gap center), there were $52 \%$ fewer

241 seedlings per $\mathrm{m}^{2}$ on average compared to the rest of the sampling strip (-10m to $\left.15 \mathrm{~m}\right)$. In this

242 zone, the average number of plots without seedlings was high, $81 \%$ for birch species and $54 \%$

243 for spruce.

244 Some significant differences among the cardinal positions of the plots ("strip orientations") and

245 the microtopography types were found, but these varied by species and according to whether the

246 plots were located within the gaps or in the residual forest stand (Tables 2 and 3). Inside the

247 gaps, northern gap positions supported significantly fewer birch seedlings than the other gap

248 positions; in the residual edge forests, western gap positions hosted the greatest density of spruce

249 seedlings than the other gap positions. Among the microtopography types, depressions hosted

250 more spruce seedlings than the other types inside the gaps (Tables 2 and 3). 


\section{Observed vegetation cover}

253 The $0-15 \mathrm{~m}$ zone inside the gaps supported the greatest number of different species groups (Fig

254 4). The edge zone in the residual edge forests favored dwarf shrubs and mosses. Gap centers

$255(\sim 15 \mathrm{~m}+)$ promoted grasses, shrubs, and herbs, creating a prolific and highly competitive

256 environment. Inside the gaps, northern gap positions were associated with a greater cover of

257 dwarf shrubs and grasses (Tables 2 and 3). In the residual edge forests, southern positions were

258 associated with a greater cover of grasses and herbs, and the eastern positions with a greater

259 cover of mosses.

260 There were a few significant differences in vegetation cover among the microtopography types

261 in the gap interior (Tables 2 and 3). The cover of shrubs was lower in depressions, while mosses

262 had greater covers on mounds, and grasses had greater covers on flat and sloped

263 microtopographies.

265 Seedling density as a function of multiple interrelated factors

266 According to the final GAM model for Norway spruce (Eq. 1 and Table 4), seedling density was

267 negatively related to the percent cover of shrubs, dwarf shrubs, grasses, and covered stones, and

268 positively related to basal area. The relationship with distance and herbs was a bit more complex

269 (Fig. 5). Among the continuous predictors, grasses was the most important. However, distance,

270 shrubs, and dwarf shrubs were almost as important. This model also indicated that the greatest

271 density of Norway spruce seedlings occurred in depressions. 
272 The final model for the number of Norway spruce seedlings per $\mathrm{m}^{2}$ that emerged after harvest,

$273 E\left(N_{\mathrm{S}}\right)$, was

274 (Eq. 1)

$\log \left(E\left(N_{\mathrm{S}}\right)\right)=\beta_{\text {Microtopo }}+f_{D}($ Distance $)+f_{S}($ Shrubs $)$

275

$+f_{D S}($ Dwarf shrubs $)+f_{H}($ Herbs $)+f_{G}($ Grasses $)$

276

$+f_{C S}($ Covered stone $)+f_{B A}($ Basal area $)$

277 where the class-specific intercepts $\beta_{\text {Microtopo }}$ are obtained from the 'Estimate' column of Table 4

278 so that $\beta_{\text {Flat }}$ is the 'Intercept' and $\beta_{\text {Microtopo }}$ of any other microtopography class is the sum of the

279 'Intercept' and the 'Estimate' value of that class. The form of the response functions $(f)$

280 estimated for the other significant predictors can be seen in Fig. 5.

281 According to the final GAM model for birch species (Eq. 2 and Table 5), seedling density was

282 negatively related to the percent covers of grasses and dwarf shrubs, and only slightly positively

283 related to basal area (Fig. 6). The relationship with distance, young stumps and decaying stumps

284 was a bit more complex. The lowest densities of birch seedlings occurred in northern gap

285 positions. Position in the gap was also found to influence the effect of distance. Therefore,

286 separate responses to functions of distance $\left(f_{D, S}\right)$ were estimated for each strip orientation $(S)$.

287 Distance was by far the most important predictor. 
288 The final model for the number of birch seedlings per $\mathrm{m}^{2}$ that emerged after harvest, $E\left(N_{\mathrm{B}}\right)$, was 289 (Eq. 2) $\log \left(E\left(N_{\mathrm{B}}\right)\right)=\beta_{\text {Strip orientation }}+f_{D, S}($ Distance $)$

292 where the parameter values $\beta_{\text {Strip orientation }}$ for the different strip orientations are obtained from the 293 'Estimate' column of Table 5, and the form of the response functions $(f)$ estimated for the other 294 significant predictors in the eastern orientation can be seen in Fig. 6. The percent cover of dwarf 295 shrubs was kept as a covariate since it produced a better AIC score (by a difference $>2$ ) than the 296 model without it. 


\section{Discussion}

\section{$300 \quad$ Modeling approach}

301 Generalized Additive Models (GAM) were applied to simultaneously assess the relative effects

302 of various gap characteristics and patterns of understory vegetation on the natural regeneration of

303 Norway spruce and birch. They proved useful in uncovering the complex relationships observed

304 in this study. However, the flexibility of GAMs, in combination with the large inherent

305 variability in seedling counts on the small plots, can result in an overestimation of the complexity

306 of relationships between variables and therefore somewhat unrealistic response curves. This is a

307 feature that GAM users need to be aware of at all stages of its application.

\section{Gradients by distance from the gap edge}

310 The strongest factor controlling seeding density for both spruce and especially birch was the

311 vicinity to the residual forest (the gap edge). Few seedlings had emerged in the residual forest

312 stand; from the edge, seedling density increased towards the gap interior, peaked, then started to

313 wane in the innermost gap regions. Additionally, GAM analyses revealed that greater residual

314 edge stand basal areas resulted in greater seedling densities overall. These findings can be

315 explained by two basic factors. First, competition from trees in the edge stand tends to limit the

316 proliferation of light-demanding understory vegetation in its vicinity, facilitating a better

317 emergence and survival of seedlings of the relatively more shade-tolerant spruce in inner-edge

318 gap regions. Second, with increasing distance from the gap edge towards the gap center, the

319 strong levels of competition exerted by prolific shrubs, dwarf shrubs, grasses and herbs on both

320 above- and below-ground resources hinders seedling growth (Jäderlund et al. 1997, Bell et al. 
321 2000, Hanssen 2003, Picon-Cochard et al. 2006), and acts as a physical impediment to seedling

322 germination and the growth of smaller seedlings (for a broader discussion of these mechanisms,

323 see Royo and Carson 2006).

324 One of the possible explanations for the distance-related pattern could be that seed rain from 325 adult trees typically diminishes with increasing distance. However, the studies by Valkonen et al. 326 (2011) and Valkonen and Siitonen (2016) have confirmed that seed dispersal distance is not an 327 important factor on such small harvest areas for any of the major forest tree species covered by 328 this study, confirming the conclusions of fundamental seed crop research (Heikinheimo 1937, 329 Lehto 1956, Perala and Alm 1990).

330 An optimal distance for seedlings was encountered at about 5-10m from the gap edge inside the 331 gap for spruce, and at about $5 \mathrm{~m}$ for birch. With increasing distance from the gap edge the 332 seedling densities tended to decrease, again likely due to the greater levels of competition from 333 understory vegetation (especially from grasses, shrubs and herbs). The findings for spruce are in 334 line with previous observations (Dai 1996, Burton 2002, Hanssen 2003, Valkonen et al. 2011). 335 As for birch, there is very little relevant previous information available. Nevertheless, also 336 having studied the early regeneration of birch seedlings (within 5 years after harvest), Huth and 337 Wagner (2006) similarly found very few birch seedlings in the central gap positions, explained 338 by high levels of competition with grasses there. In slight contrast to our results, Valkonen et al.

339 (2011) studied birch regeneration 10 years after harvest (twice as long as the regeneration period

340 of this study) in $40 \mathrm{~m} \times 40 \mathrm{~m}$ gaps, and found that the number of birch seedlings steadily

341 increased from the gap edge towards the gap center. It can therefore be speculated that in the 342 early regeneration phases of birch seedlings, the positive influence of potential light resources in 343 the central gap positions is outweighed by the negative pressures of competition from dense 
344 understory vegetation. In the later regeneration phases, however, the spatial patterns of

345 successful seedling regeneration may more closely reflect the availability of light resources

346 across the gap.

348 Position in the gap and microtopography

349 Variation in the abundance and composition of understory vegetation, as well as the gradient in

350 distance from gap edge affected the observed natural tree regeneration. The cardinal position of

351 the sample plots (with respect to the gap midpoint) influenced both the seedling density and the

352 abundance of understory vegetation in variable ways. Some patterns and correlations were

353 somewhat vague and hard to interpret unambiguously. However, some rather obvious patterns

354 are worth mentioning. The greater spruce seedling densities observed in the western portions of

355 the residual stand were likely due to the significantly lower herb cover observed there. Northern

356 gap positions hosted low densities of birch seedlings. This result was somewhat unexpected,

357 because birch species have a very low shade tolerance and in these latitudes the northern gap

358 positions would presumably favour their exposure to light (Canham et al. 1990). However,

359 Friesen and Michaels (2010) showed that the light-demanding Scots pine similarly did not

360 generally benefit from the greater exposure to light in northern gap positions, signaling that other

361 factors play a greater role in its regeneration. Similarly, other studies have reported a shift in the

362 composition of understory vegetation towards the northern gap regions (Fahey and Puettmann

363 2008, Friesen and Michaels 2010).

364 In terms of microtopography, the greatest density of Norway spruce seedlings was observed in 365 depressions, a finding that is in line with the results of several other studies (Hanssen 2003, 
366 Kuuluvainen and Kalmari 2003, Diaci et al. 2005). This can be explained in part by the fact that

367 depressions had significantly lower covers of shrubs and grasses. From small to moderate covers, 368 microsites of covered stones promoted higher than average Norway spruce seedling densities,

369 but this effect became negative with greater coverage. Both young and decaying stumps/logs

370 were favorable microsites for birch seedlings, as found in previous studies by Liu and Hytteborn

371 (1991), Grenfell et al. (2011), and Robert et al. (2012). However, in this study the effect was

372 unimodal, peaking at 10-15\% cover, then waning with greater coverage.

374 Limitations of the study

375 First, seed crops in the area for the study period (2010-2015) can be described as having been 376 average for birch but slightly more abundant than average for Norway spruce, which had three

377 modestly abundant crops (in 2011, 2013, and 2015) alternating with poor crops (2010, 2012, and

378 2014) (personal communication, Tatu Hokkanen, Natural Resources Institute Finland, Luke).

379 Second, the observed microsites, edge effects, and patterns of understory vegetation across the

380 gap environment will no doubt change as the gap ages. As a result, features that currently

381 promote high numbers of seedlings will not necessarily support the most successful regeneration 382 over time, and vice versa.

\section{Conclusions}

385 Our results suggest adequate potential for natural regeneration in harvested gaps under similar 386 conditions if carried out with attention to several factors which may impede or promote natural 387 regeneration. The emergence of spruce and birch seedlings seems abundant within the $0-15 \mathrm{~m}$ 19 
388 zone inside the gap. However, the inner gap region beyond $15 \mathrm{~m}$ from the edge was

389 characterized by limited seedling establishment, likely owing to the high levels of competition

390 with understory vegetation. As a result, we recommend that harvested gap diameters should not

391 exceed $40 \mathrm{~m}$ in order to minimize the proliferation of competitive understory vegetation and to

392 favor successful initial seedling establishment on mesic and submesic sites in Southern Finland.

393 While these small gap sizes would be instrumental in promoting early seedling establishment,

394 further expansion of the gaps through subsequent silvicultural interventions will likely be needed

395 in order to provide established seedlings with greater access to resource (e.g., light) and to

396 promote successful long-term regeneration.

\section{Acknowledgements}

399 Falling under the umbrella of the long-term DISTDYN project, this study received important

400 practical and financial support from the Natural Resources Institute Finland (Luke) and

401 Metsähallitus, without which the research would not have been possible. We are grateful to both

402 Dr. Tiina Tonteri (Luke) and Dr. Pasi Puttonen (Department of Forest Sciences, University of

403 Helsinki) for their insight and guidance during the research design phases. Very special thanks to

404 Hilkka Ollikainen (Luke) for her experienced and knowledgeable contribution throughout the

405 entire data-collection process, and to Ilkka Vanha-Majamaa for his comments on the manuscript. 


\section{References}

Attiwill, P. 1994. The disturbance of forest ecosystems: the ecological basis for conservative management. Forest Ecology and Management 63(2-3): 247-300. doi: 10.1016/0378$1127(94) 90114-7$.

Bell, F.W., Ter-Mikaelian, M.T., and Wagner, R.G. 2000. Relative competitiveness of nine early-successional boreal forest species associated with planted jack pine and black spruce seedlings. Canadian Journal of Forest Research 30(5): 790-800. doi:10.1139/x00-004.

Bergeron, Y., Leduc, A., Harvey, B., and Gauthier, S. 2002. Natural fire regime: a guide for sustainable forest management of the Canadian boreal forest. Silva Fennica 36: 81-95.

Burton, P.J. 2002. Effects of clearcut edges on trees in the sub-boreal spruce zone of Northwest-Central British Columbia. Silva Fennica 36(1): 329-352. doi:10.14214/sf.566.

Cajander, A.K. 1909. Über Waldtypen [Forest site types]. Acta Forestalia Fennica 1: 1-175.

Canham, C.D., Denslow, J.S., Platt, W.J., Runkle, J.R., Spies, T.A., and White, P.S. 1990. Light regimes beneath closed canopies and tree-fall gaps in temperate and tropical forests. Canadian Journal of Forest Research 20(5): 620-631. doi:10.1139/x90-084.

Dai, X. 1996. Influence of light conditions in canopy gaps on forest regeneration: A new gap light index and its application in a boreal forest in east-central Sweden. Forest Ecology and Management 84(1-3): 187-197. doi:10.1016/0378-1127(96)03734-6.

De Chantal, M., Leinonen, K., Kuuluvainen, T., and Cescatti, A. 2003. Early response of Pinus sylvestris and Picea abies seedlings to an experimental canopy gap in a boreal spruce 
forest. Forest Ecology and Management 176(1-3): 321-336. doi:10.1016/s03781127(02)00273-6.

Diaci, J., Pisek, R., and Boncina, A. 2005. Regeneration in experimental gaps of subalpine Picea abies forest in the Slovenian Alps. European Journal of Forest Research 124(1): 29-36. doi:10.1007/s10342-005-0057-7.

Domke, G.M., Caspersen, J.P., and Jones, T.A. 2007. Light attenuation following selection harvesting in northern hardwood forests. Forest Ecology and Management 239(1-3): 182190. doi:10.1016/j.foreco.2006.12.006.

Fahey, R.T., and Puettmann, K.J. 2008. Patterns in spatial extent of gap influence on understory plant communities. Forest Ecology and Management 255(7): 2801-2810. doi:10.1016/j.foreco.2008.01.053.

Friesen, C., and Michaels, N. 2010. Effects of Incorporating Gaps into Commercial Thinning Prescriptions: Best Available Science. Central Cascades Adaptive Management Partnership (CCAMP). Available from http://ecoshare.info/projects/central-cascade-adaptivemanagement-partnership/synthesis-papers-tools/ [accessed 10 January 2014].

Grenfell, R., Aakala, T., and Kuuluvainen, T. 2011. Microsite occupancy and the spatial structure of understorey regeneration in three late-successional Norway spruce forests in Northern Europe. Silva Fennica 45(5): 1093-1110. doi:10.14214/sf.89.

Grömping, U. 2006. Relative importance for linear regression in R: The package relaimpo. Journal of Statistical Software 17(1): 1-27. doi:10.18637/jss.v017.i01. 
Grushecky, S.T., and Fajvan, M.A. 1999. Comparison of hardwood stand structure after partial harvesting using intensive canopy maps and geostatistical techniques. Forest Ecology and Management 114(2-3): 421-432. doi:10.1016/S0378-1127(98)00372-7.

Halpern, C.B., McKenzie, D., Evans, S.A., and Maguire, D.A. 2005. Initial responses of forest understories to varying levels and patterns of green-tree retention. Ecological Applications 15(1): 175-195. doi:10.1890/03-6000.

Hanssen, K.H. 2003. Natural regeneration of Picea abies on small clear-cuts in SE Norway. Forest Ecology and Management 180(1-3): 199-213. doi:10.1016/s0378-1127(02)00610-2.

Heikinheimo, O. 1937. Metsäpuiden siementämiskyvystä II. Referat: Über die Besanmungsfähigkeit der Waldbäume II. [Seed production capacity of forest trees]. Communicationes Instituti Forestalis Fenniae 24(4): 67. Finnish with German summary.

Hill, S.B., Mallik, A.U., and Chen, H.Y.H. 2005. Canopy gap disturbance and succession in trembling aspen dominated boreal forests in northeastern Ontario. Canadian Journal of Forest Research 35(8): 1942-1951. doi:10.1139/x05-126.

Huth, F., and Wagner, S. 2006. Gap structure and establishment of Silver birch regeneration (Betula pendula Roth.) in Norway spruce stands (Picea abies L. Karst.). Forest Ecology and Management 229(1-3): 314-324. doi:10.1016/j.foreco.2006.04.010.

Koivula, M., Kuuluvainen, T., Hallman, E., Kouki, J., Siitonen, J., and Valkonen, S. 2014. Forest management inspired by natural disturbance dynamics (DISTDYN) - a long-term research and development project in Finland. Scandinavian Journal of Forest Research 29(6): 579-592. doi:10.1080/02827581.2014.938110. 
Kuuluvainen, T. 1994. Gap disturbance, ground microtopography, and the regeneration dynamics of boreal coniferous forests in Finland: a review. Annales Zoologici Fennici 31: 35-51. Available from http://www.jstor.org/stable/23735497 [accessed 4 February 2014]. Kuuluvainen, T., and Aakala, T. 2011. Natural forest dynamics in boreal Fennoscandia: a review and classification. Silva Fennica 45: 823-841.

Kuuluvainen, T., and Kalmari, R. 2003. Regeneration microsites of Picea abies seedlings in a windthrow area of a boreal old-growth forest in southern Finland. Annales Botanici Fennici 40: 401-413. Available from http://www.jstor.org/stable/23726798 [accessed 20 March 2014].

Lehto, J. 1956. Tutkimuksia männyn luontaisesta uudistumisesta Etelä-Suomen kangasmailla. Summary: Studies on the natural reproduction of Scots pine on the upland soils of Southern Finland. Acta Forestalia Fennica 66(2) 106.

Liu, Q., and Hytteborn, H. 1991. Gap structure, disturbance and regeneration in a primeval Picea abies forest. Journal of Vegetation Science 2(3): 391-402. doi:10.2307/3235932.

Long, J. 2009. Emulating natural disturbance regimes as a basis for forest management: a North American view. Forest Ecology and Management 257: 1868-1873.

Palmer, M.W., and Dixon, P.M. 1990. Small-Scale Environmental Heterogeneity and the Analysis of Species Distributions along Gradients. Journal of Vegetation Science 1(1): $57-$ 65. doi: $10.2307 / 3236053$. 
Perala D., and Alm, A. 1990. Regeneration silviculture of birch: a review. Forest Ecology and Management 32(1): 39-77.

Picon-Cochard, C., Coll, L., and Balandier, P. 2006. The role of below-ground competition during early stages of secondary succession: The case of 3-year-old Scots pine (Pinus sylvestris L.) seedlings in an abandoned grassland. Oecologia 148(3): 373-383. doi:10.1007/s00442-006-0379-2.

R Core Team 2014. R: A language and environment for statistical computing. R Foundation for Statistical Computing, Vienna, Austria.

Raymond, P., Munson, A.D., Ruel, J.-C., and Coates, K.D. 2006. Spatial patterns of soil microclimate, light, regeneration, and growth within silvicultural gaps of mixed tolerant hardwood - white pine stands. Canadian Journal of Forest Research 36: 639-651.

Robert, E., Brais, S., Harvey, B.D., and Greene, D. 2012. Seedling establishment and survival on decaying logs in boreal mixedwood stands following a mast year. Canadian Journal of Forest Research 42(8): 1446-1455. doi:10.1139/x2012-085.

Robinson, A.P., Lane, S.E., and Thérien, G. 2011. Fitting forestry models using generalized additive models: a taper model example. Canadian Journal of Forest Research 41: 1909_ 1916. doi: https://doi.org/10.1139/x11-095.

Royo, A.A., and Carson, W.P. 2006. On the formation of dense understory layers in forests worldwide: consequences and implications for forest dynamics, biodiversity, and succession. Canadian Journal of Forest Research 36: 1345-1362. 
Runkle, J.R. 1981. Gap regeneration in some old-growth forests of the eastern United States. Ecology 62: 1041-1051. doi:10.2307/1937003.

Stewart, K.J., and Mallik, A.U. 2006. Bryophyte responses to microclimatic edge effects across riparian buffers. Ecological Applications 16(4): 1474-1486. doi:10.1890/10510761(2006)016[1474:brtmee]2.0.co;2.

Tonteri, T. 1994. Species richness of boreal understorey forest vegetation in relation to site type and successional factors. Annales Zoologici Fennici 31: 53-60. Available from http://www.jstor.org/stable/23735498?seq=1\#page_scan_tab_contents [accessed 4 February $2014]$.

Valkonen, S., Koskinen, K., Mäkinen, J., and Vanha-Majamaa, I. 2011. Natural regeneration in patch clear-cutting in Picea abies stands in Southern Finland. Scandinavian Journal of Forest Research 26(6): 530-542. doi:10.1080/02827581.2011.611818.

Valkonen, S., and Siitonen, J. 2016. Tree regeneration in patch cutting in Norway spruce stands in northern Finland. Scandinavian Journal of Forest Research 31: 271-278.

Vanha-Majamaa, I., Shorohova, E., Kushnevskaya, H., and Jalonen, J. 2017. Resilience of understory vegetation after variable retention felling in boreal Norway spruce forests - A tenyear perspective. Forest Ecology and Management 393: 12-28.

Wood, S.N. 2006. Generalized Additive Models: An Introduction with R. Chapman and Hall/CRC, Boca Raton, Florida. 
Wood, S.N. 2011. Fast stable restricted maximum likelihood and marginal likelihood estimation of semiparametric generalized linear models. Journal of the Royal Statistical Society (B) 73 (1): 3-36. doi:10.1111/j.1467-9868.2010.00749.x.

Zasada, J.C., Sharik, T.L., and Nygren, M. 1992. The reproductive process in boreal forest trees. In A Systems Analysis of the Global Boreal Forest. Edited by G.B. Bonan. Cambridge University Press, Cambridge, UK. pp. 85-125. 
Table 1. Overview of the study's variables at measurement 4-5 years after harvesting.

\begin{tabular}{|c|c|c|c|c|}
\hline Variable* & Mean & SD & Min & Max \\
\hline Basal area (edge stand) & 23.58 & 2.93 & 18.00 & 32.0 \\
\hline $\begin{array}{l}\text { Tree regeneration } \\
\text { Norway spruce }\end{array}$ & 2.07 & 5.49 & 0.00 & 71.0 \\
\hline After harvest & 1.77 & 5.36 & 0.00 & 71.0 \\
\hline Germinants & 1.38 & 4.15 & 0.00 & 59.0 \\
\hline Birch spp. & 0.54 & 1.68 & 0.00 & 16.0 \\
\hline After harvest & 0.37 & 1.35 & 0.00 & 15.0 \\
\hline Germinants & 0.12 & 0.78 & 0.00 & 13.0 \\
\hline $\begin{array}{l}\text { Vegetation cover } \\
\text { Shrubs }\end{array}$ & 9.23 & 19.72 & 0.00 & 98.0 \\
\hline Rubus idaeus & 9.17 & 19.63 & 0.00 & 98.0 \\
\hline Dwarf shrubs & 11.37 & 14.30 & 0.00 & 77.0 \\
\hline Calluna vulgaris & 0.15 & 1.26 & 0.00 & 23.0 \\
\hline V. myrtillus & 6.85 & 9.84 & 0.00 & 74.0 \\
\hline V. vitis idaea & 4.35 & 7.91 & 0.00 & 76.0 \\
\hline Herbs & 7.73 & 11.55 & 0.00 & 94.0 \\
\hline E. angustifolium & 3.21 & 9.35 & 0.00 & 89.0 \\
\hline Grasses & 17.73 & 26.27 & 0.00 & 99.0 \\
\hline Calamagrostis spp. & 13.69 & 22.29 & 0.00 & 99.0 \\
\hline Ferns & 1.35 & 5.60 & 0.00 & 74.0 \\
\hline Mosses & 45.88 & 32.53 & 0.00 & 100.0 \\
\hline Dicranum spp. & 2.34 & 3.59 & 0.00 & 37.0 \\
\hline H. splendens & 21.31 & 24.09 & 0.00 & 98.0 \\
\hline P. shreberi & 16.98 & 19.43 & 0.00 & 96.0 \\
\hline Lichens & 0.37 & 1.00 & 0.00 & 8.0 \\
\hline $\begin{array}{l}\text { Microsite cover } \\
\text { Covered stone }\end{array}$ & 47.22 & 33.94 & 0.00 & 100.0 \\
\hline Bare stone & 0.79 & 4.35 & 0.00 & 81.0 \\
\hline Tree base & 0.72 & 3.59 & 0.00 & 49.0 \\
\hline Logs & 5.59 & 8.75 & 0.00 & 68.0 \\
\hline Young stumps & 0.80 & 2.58 & 0.00 & 26.0 \\
\hline Decaying stumps & 2.19 & 5.06 & 0.00 & 37.0 \\
\hline Duff & 27.42 & 23.10 & 1.00 & 97.0 \\
\hline Slash & 7.90 & 18.34 & 0.00 & 97.0 \\
\hline Bare mineral soil & 0.06 & 1.37 & 0.00 & 40.0 \\
\hline Bare humus & 0.35 & 2.47 & 0.00 & 58.0 \\
\hline
\end{tabular}

${ }^{*}$ Note: Basal area is given in $\mathrm{m}^{2} \mathrm{ha}^{-1}$ at stand level, tree regeneration values in number of individuals $\mathrm{m}^{-2}$, vegetation and microsite cover values in $\%$ at plot level. 
Table 2. Statistical significance ( $p$ ) of differences between strip orientations and microtopography types on the basis of Kruskal-Wallis one-way ANOVA. The analyses were conducted separately for sample plots in the interior of the gaps (inside) and for those in the residual forest stand (outside). Significant $p$ values $<0.05$ in bold.

\begin{tabular}{|c|c|c|c|c|c|c|c|c|c|c|}
\hline \multirow{4}{*}{ Factor } & \multirow{4}{*}{ Position } & \multicolumn{9}{|c|}{ Response } \\
\hline & & \multicolumn{2}{|c|}{$\underset{\mathrm{m}^{-2}}{\text { Seedling density }}$} & \multirow[b]{2}{*}{ Shrubs } & \multirow[b]{2}{*}{$\begin{array}{l}\text { Dwarf } \\
\text { shrubs }\end{array}$} & \multirow[b]{2}{*}{ Herbs } & \multirow{2}{*}{$\begin{array}{l}\text { Cover, \% } \\
\text { Grasses }\end{array}$} & \multirow[b]{2}{*}{ Ferns } & \multirow[b]{2}{*}{ Mosses } & \multirow[b]{2}{*}{ Lichens } \\
\hline & & $\begin{array}{l}\text { Norway } \\
\text { spruce }\end{array}$ & $\begin{array}{l}\text { Birch } \\
\text { spp. }\end{array}$ & & & & & & & \\
\hline & & & & & & $p$ & & & & \\
\hline \multirow{2}{*}{$\begin{array}{l}\text { Strip } \\
\text { orientation }\end{array}$} & inside & 0.735 & 0.003 & 0.268 & 0.004 & 0.169 & 0.017 & 0.093 & 0.282 & 0.251 \\
\hline & outside & 0.018 & 0.292 & 0.670 & 0.164 & 0.009 & 0.020 & 0.313 & 0.006 & 0.233 \\
\hline \multirow{2}{*}{$\begin{array}{l}\text { Micro- } \\
\text { topography } \\
\text { type }\end{array}$} & inside & 0.011 & 0.391 & 0.012 & 0.134 & 0.297 & 0.001 & 0.596 & 0.047 & 0.092 \\
\hline & outside & 0.576 & 0.026 & 0.410 & 0.189 & 0.232 & 0.690 & 0.081 & 0.354 & 0.834 \\
\hline
\end{tabular}


Table 3. Mean value of the response variable for each strip orientation or microtopography type for those combinations of factor, position, and response where significant differences were reported in Table 2 . The results of pairwise comparisons by Tukey's post-hoc test are indicated by lowercase letters following the mean values: if two values of the same row share a common letter, then they are not significantly different in a pairwise comparison.

\begin{tabular}{|c|c|c|c|c|c|}
\hline \multirow{2}{*}{ Position } & \multirow{2}{*}{ Response } & \multicolumn{4}{|c|}{ Strip orientation } \\
\hline & & N & $E$ & $S$ & W \\
\hline \multirow{3}{*}{ inside } & Birch spp. & $0.16 a$ & $0.62 \mathrm{ac}$ & $0.94 \mathrm{bc}$ & $1.04 \mathrm{c}$ \\
\hline & Dwarf shrubs & $12.77 a$ & $8.27 \mathrm{~b}$ & $8.97 a b$ & $6.28 \mathrm{~b}$ \\
\hline & Grasses & $30.92 a$ & $19.62 b$ & $27.26 a b$ & $23.62 a b$ \\
\hline \multirow{4}{*}{ outside } & Norway spruce & $1.35 a$ & $1.50 \mathrm{a}$ & $1.42 a$ & $3.42 \mathrm{~b}$ \\
\hline & Herbs & 4.10ab & $3.18 a b$ & $4.68 a$ & $3.05 b$ \\
\hline & Grasses & $2.56 a$ & $3.42 a$ & $6.90 \mathrm{~b}$ & $2.44 a$ \\
\hline & Mosses & $66.33 a$ & $77.41 \mathrm{~b}$ & $60.88 a$ & 70.01ab \\
\hline \multirow{2}{*}{ Position } & \multirow{2}{*}{ Response } & \multicolumn{4}{|c|}{ Microtopography type } \\
\hline & & Flat & Slope & Depression & Mound \\
\hline \multirow{4}{*}{ inside } & Norway spruce & $2.34 a$ & $1.03 a$ & $7.00 \mathrm{~b}$ & $1.62 a$ \\
\hline & Shrubs & $14.03 a$ & $15.36 a$ & $5.86 \mathrm{bc}$ & $13.06 \mathrm{ac}$ \\
\hline & Grasses & $28.54 a$ & $24.29 a$ & $11.89 \mathrm{~b}$ & $11.74 b$ \\
\hline & Mosses & $32.57 a$ & $31.99 a$ & $35.41 a$ & $43.79 a$ \\
\hline outside & Birch spp. & $0.21 \mathrm{ab}$ & $0.25 a b$ & $0.00 a$ & $0.52 b$ \\
\hline
\end{tabular}


Table 4. Summary of the GAM for the number of Norway spruce seedlings per $\mathrm{m}^{2}$ which emerged after harvest.

\begin{tabular}{lllll}
\hline \multicolumn{5}{c}{ Parametric coefficients $^{*}$ : } \\
\hline \multirow{5}{*}{ Intercept } & Estimate & Std. Error & z value & $\operatorname{Pr}(>|z|)$ \\
\cline { 2 - 5 } Microtopo $_{\text {Slope }}$ & 0.08117 & 0.09923 & 0.818 & 0.41338 \\
Microtopo $_{\text {Depression }}$ & -0.45819 & 0.19991 & -2.292 & $0.02191^{*}$ \\
Microtopo $_{\text {Mound }}$ & 1.08783 & 0.37806 & 2.877 & $0.00401^{* *}$ \\
\hline \multicolumn{5}{c}{ Approximate significance of smooth terms: } \\
\hline s(distance) & 0.50308 & 0.24699 & 2.037 & $0.04166^{*}$ \\
s(shrubs) & edf ${ }^{\dagger}$ & Chi.sq & $p$-value & Relative importance, \% \\
\cline { 2 - 5 } s(dwarf shrubs) & 4.729 & 27.194 & $0.000122^{* * *}$ & 3.9 \\
s(herbs) & 1.000 & 32.618 & $1.12 \mathrm{e}-08^{* * *}$ & 4.2 \\
s(grasses) & 1.002 & 30.891 & $2.81 \mathrm{e}-08^{* * *}$ & 3.9 \\
s(covered stone) & 3.579 & 11.526 & $0.028751^{*}$ & 1.5 \\
s(basal area) & 2.854 & 46.215 & $2.32 \mathrm{e}-09^{* * *}$ & 5.9 \\
\hline Observations & 1.000 & 20.321 & $6.56 \mathrm{e}-06^{* * *}$ & 2.5 \\
Deviance explained & 1.470 & 9.215 & $0.008566^{* *}$ & 1.0 \\
\hline
\end{tabular}

* Estimates of the parametric coefficients: 'Intercept' is the mean value in the reference category Flat, whereas Microtopo Slope $_{\text {, Microtopo }}$ Depression and Microtopo ${ }_{\text {Mound }}$ are the difference between the Intercept and the mean of the Slope, Depression and Mound categories, respectively.

${ }^{\dagger}$ Estimated degrees of freedom (edf) for the cubic spline smoothers; ranges from edf $=1$ (the GAM estimates that a single slope parameter explains the relationship, i.e. it is linear) to edf $=\mathrm{n}-1$ (the GAM estimates that a unique parameter is required to fit each observation, i.e. the relationship is highly non-linear).

Note: $* p<0.05 ; * * p<0.01 ; * * * p<0.001$ 
Table 5. Summary of the GAM for the number of birch seedlings per $\mathrm{m}^{2}$ which emerged after harvest.

\begin{tabular}{|c|c|c|c|c|}
\hline \multicolumn{5}{|c|}{ Parametric coefficients ${ }^{*}$ : } \\
\hline & Estimate & Std. Error & $z$ value & $\operatorname{Pr}(>|z|)$ \\
\hline Intercept & -2.2845 & 0.2819 & -8.105 & $5.29 \mathrm{e}-16^{* * *}$ \\
\hline Strip $_{\text {East }}$ & 0.6415 & 0.3635 & 1.765 & 0.0776 \\
\hline Strip ${ }_{\text {South }}$ & 0.2029 & 0.5586 & 0.363 & 0.7164 \\
\hline Strip West & 0.8285 & 0.3621 & 2.288 & 0.0221 * \\
\hline \multicolumn{5}{|c|}{ Approximate significance of smooth terms: } \\
\hline & $e d f^{\dagger}$ & Chi.sq & $p$-value & Relative importance, $\%$ \\
\hline s(distance): Strip North & 1.000 & 1.120 & 0.28994 & \multirow{4}{*}{14.3} \\
\hline $\mathrm{s}\left(\right.$ distance): Strip $\mathrm{East}_{\mathrm{f}}$ & 3.025 & 12.553 & 0.01190 * & \\
\hline $\mathrm{s}$ (distance): Strip ${ }_{\text {South }}$ & 3.507 & 13.585 & 0.01218 * & \\
\hline $\mathrm{s}$ (distance): Strip ${ }_{\text {West }}$ & 3.444 & 18.435 & 0.00143 ** & \\
\hline$s($ dwarf shrubs $)$ & 1.689 & 5.693 & 0.06500 & 1.4 \\
\hline $\mathrm{s}$ (grasses) & 1.001 & 3.854 & $0.04983 *$ & 0.8 \\
\hline $\mathrm{s}$ (young stumps) & 1.176 & 11.822 & 0.00136 ** & 2.2 \\
\hline s(decayed stump) & 2.646 & 13.689 & 0.00471 ** & 3.2 \\
\hline $\mathrm{s}($ basal area) & 1.000 & 1.636 & 0.20085 & 0.3 \\
\hline Observations & 876 & & & \\
\hline Deviance explained & $31.6 \%$ & & & \\
\hline
\end{tabular}

* Estimates of the parametric coefficients: 'Intercept' is the mean value in the reference category North, whereas

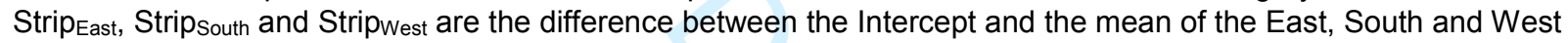
categories, respectively.

${ }^{\dagger}$ Estimated degrees of freedom (edf) for the cubic spline smoothers; ranges from edf $=1$ (the GAM estimates that a single slope parameter explains the relationship, i.e. it is linear) to edf $=\mathrm{n}-1$ (the GAM estimates that a unique parameter is required to fit each observation, i.e. the relationship is highly non-linear).

Note: $* \mathrm{p}<0.05 ; * * \mathrm{p}<0.01 ; * * * \mathrm{p}<0.001$ 


\section{Figure captions}

Figure 1. An example of harvesting in the 50\% intermediate-scale disturbance block (here referred to as OH50\% using Finnish terminology). Gaps are shown in red ("Pienaukko" in Finnish, as seen in the legend), and partial harvests in green ("Osittaushakkuu"); the light brown areas represent first commercial thinning ("Ensiharvennus"), and the dark brown represents thinning in the residual stand ("Välialueen harvennus").

Figure 2. Experimental setup for gap analysis.

Figure 3. Mean seedling density in relation to gap edge (seen here as the dotted line).

Figure 4. Mean percent cover of species groups as a function of distance from gap edge (seen here as the dotted line).

Figure 5. Estimated seedling density $\left(\mathrm{per}^{2}\right)$ for spruce which emerged after harvest as a function of GAM covariates, fixed for flat topography. Shaded bands indicate the $95 \%$ confidence intervals. Distance $=$ distance of plot $i$ from the gap edge (m); Basal area $=$ basal area of the residual forest surrounding the gap of plot $\mathrm{i}\left(\mathrm{m}^{2} \mathrm{ha}^{-1}\right)$; Shrubs, Dwarf shrubs, Herbs, Grasses $=$ percent cover of each species group on plot $i(\%)$; and Covered stone $=$ percent cover of this microsite type on plot $i(\%)$.

Figure 6. Estimated seedling density $\left(\right.$ per $\mathrm{m}^{2}$ ) for birch which emerged after harvest as a function of GAM covariates, fixed for an eastern strip orientation. Shaded bands indicate the $95 \%$ confidence intervals. Strip = orientation class of sampling strip of plot $i$ (North, South, East, West); and Young stumps, Decaying stumps = percent cover of these microsite types on plot $i$ (\%); others are as explained in Fig. 5 caption. 
Fig. 1.

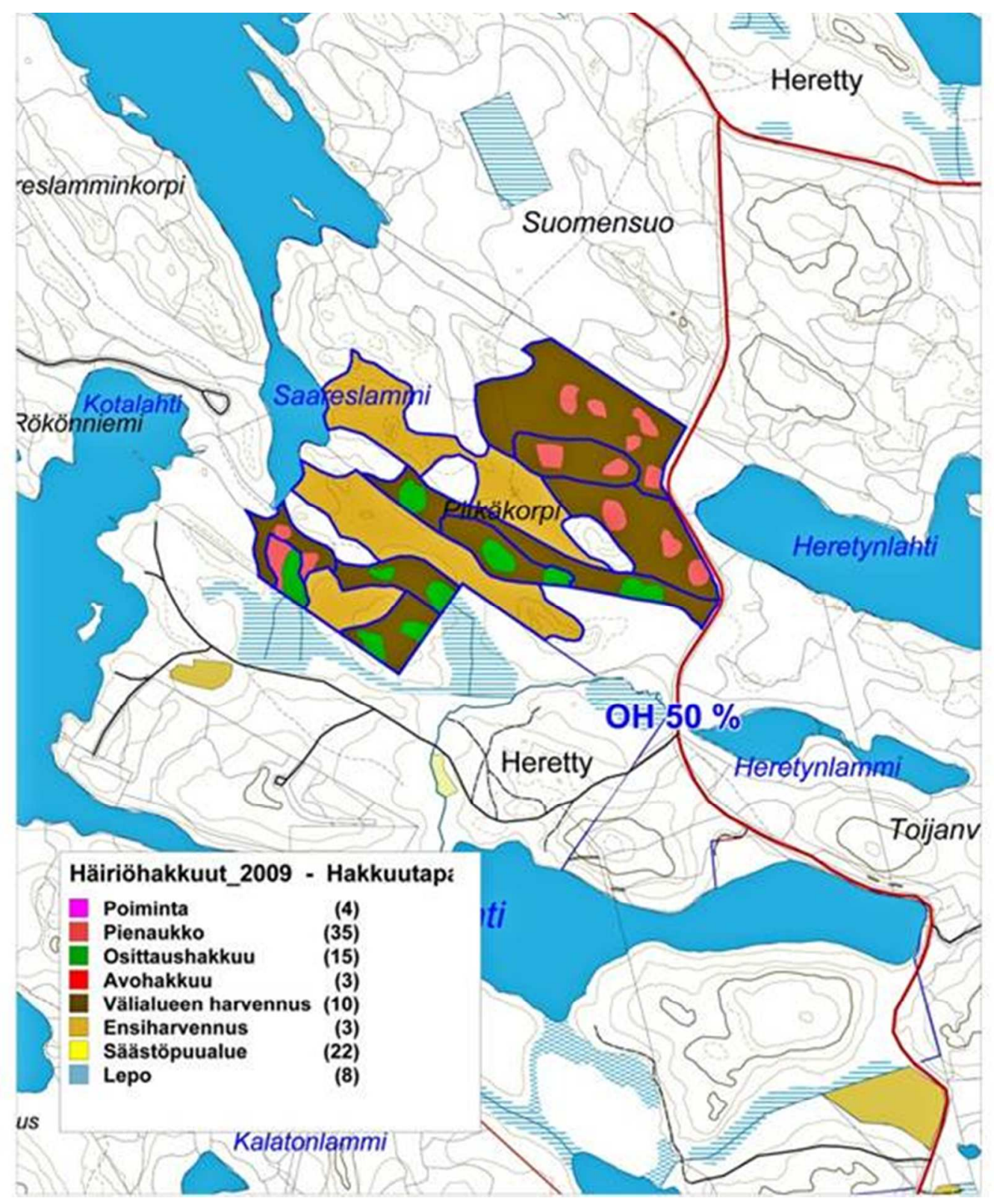

Figure 1. An example of harvesting in the 50\% intermediate-scale disturbance block (here referred to as $\mathrm{OH} 50 \%$ using Finnish terminology). Gaps are shown in red ("Pienaukko" in Finnish, as seen in the legend) and partial harvests in green ("Osittaushakkuu"); the light brown areas represent first commercial thinning ("Ensiharvennus"), and the dark brown represents thinning in the residual stand ("Välialueen harvennus"). 
Fig. 2.

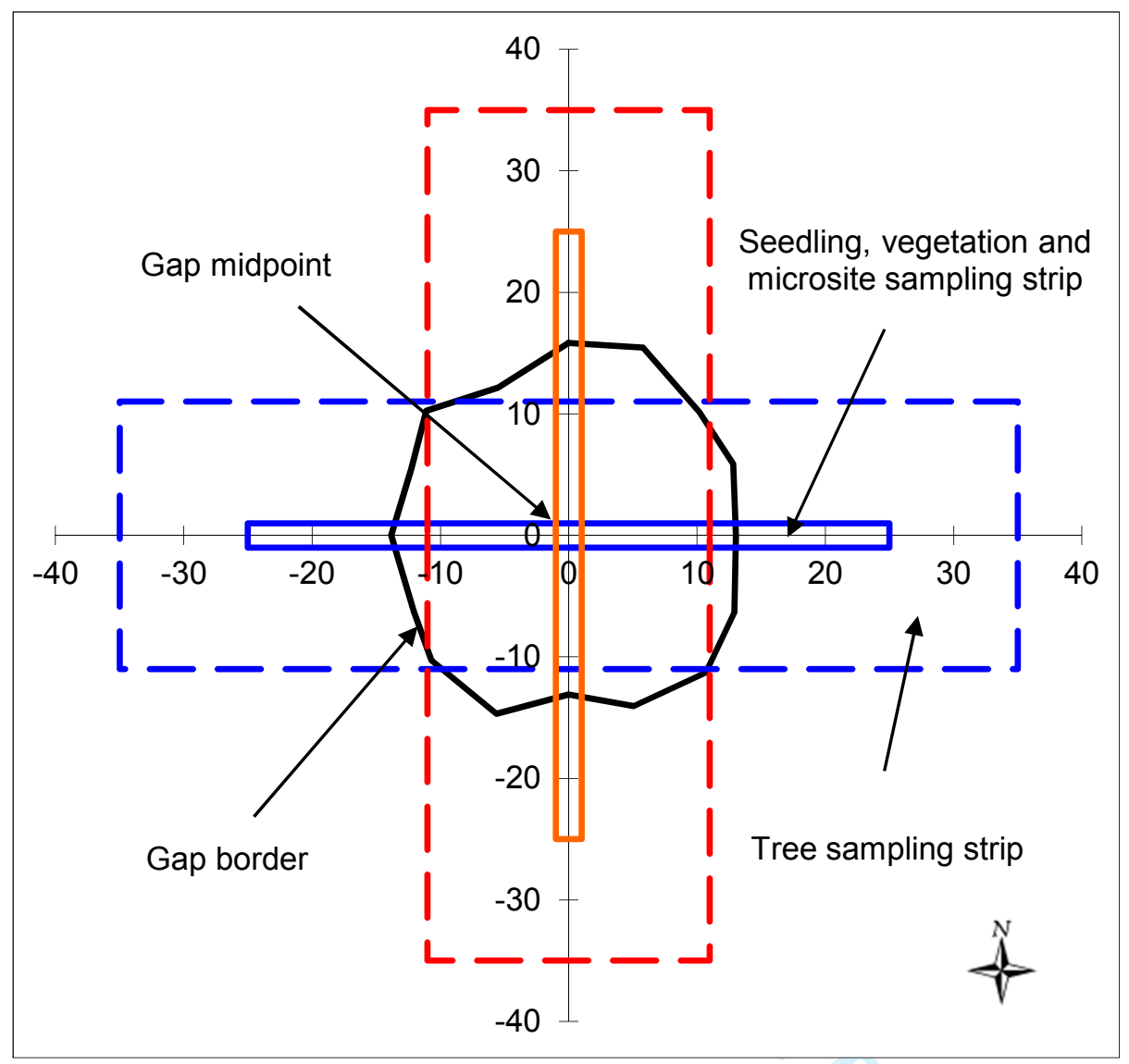

Figure 2. Experimental setup for gap analysis. 
Fig. 3.

a. Norway Spruce (Picea abies L.)

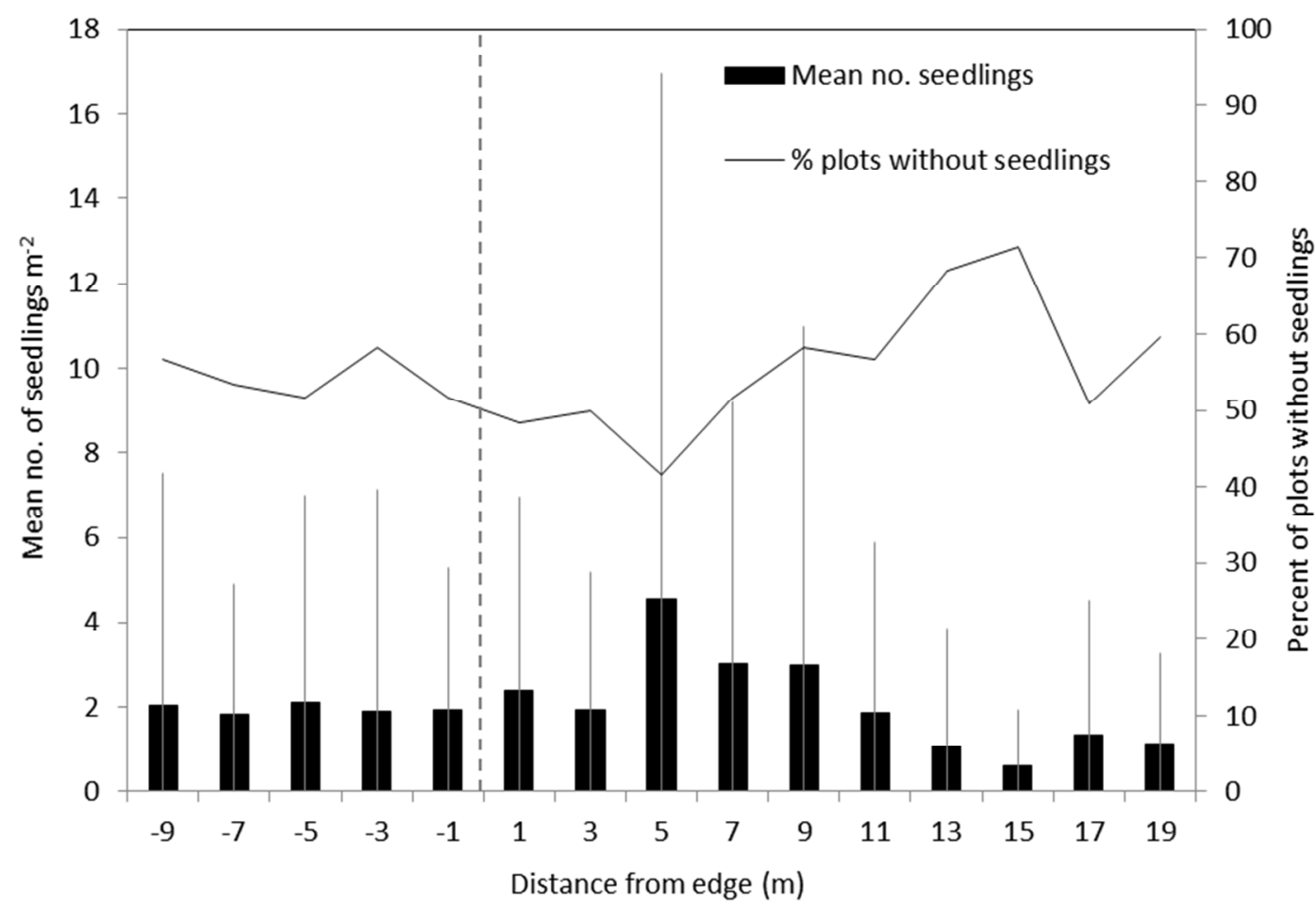

b. Birch spp. (Betula pendula Roth. \& Betula pubescens Ehrh.)

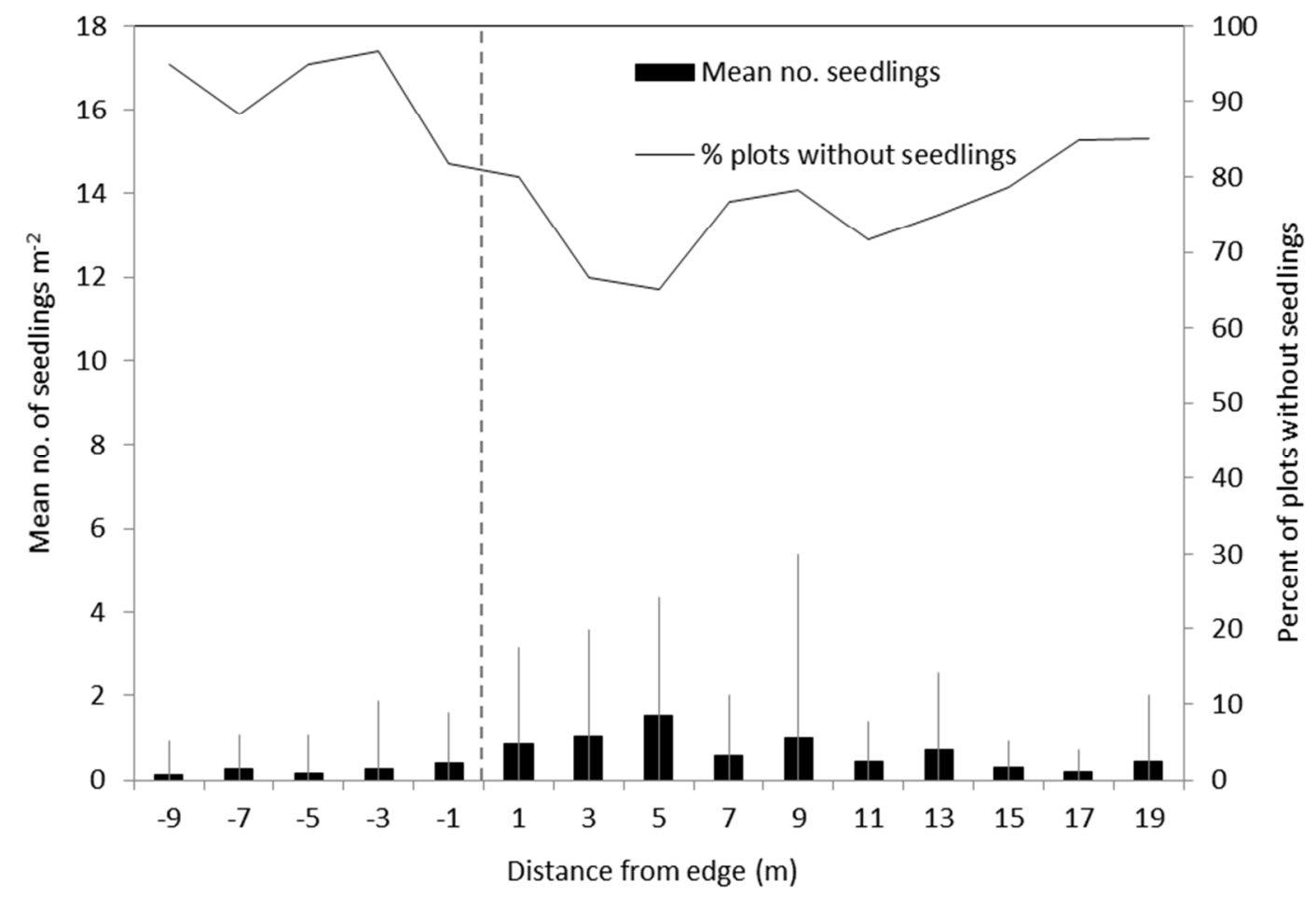

Figure 3. Mean seedling density in relation to gap edge (seen here as the dotted line). 
Fig. 4.
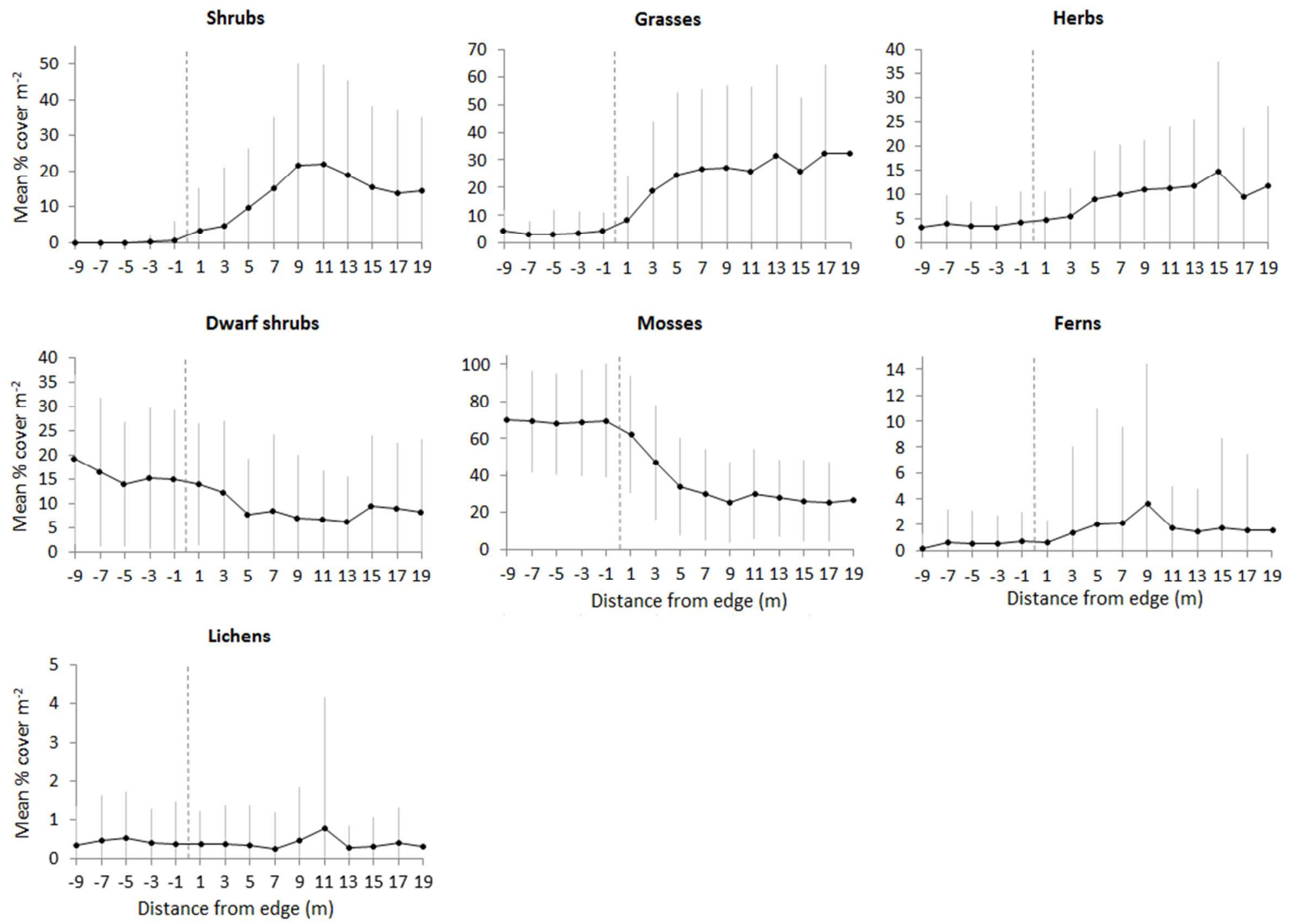

Figure 4. Mean percent cover of species groups as a function of distance from gap edge (seen here as the dotted line). 
Fig.5.
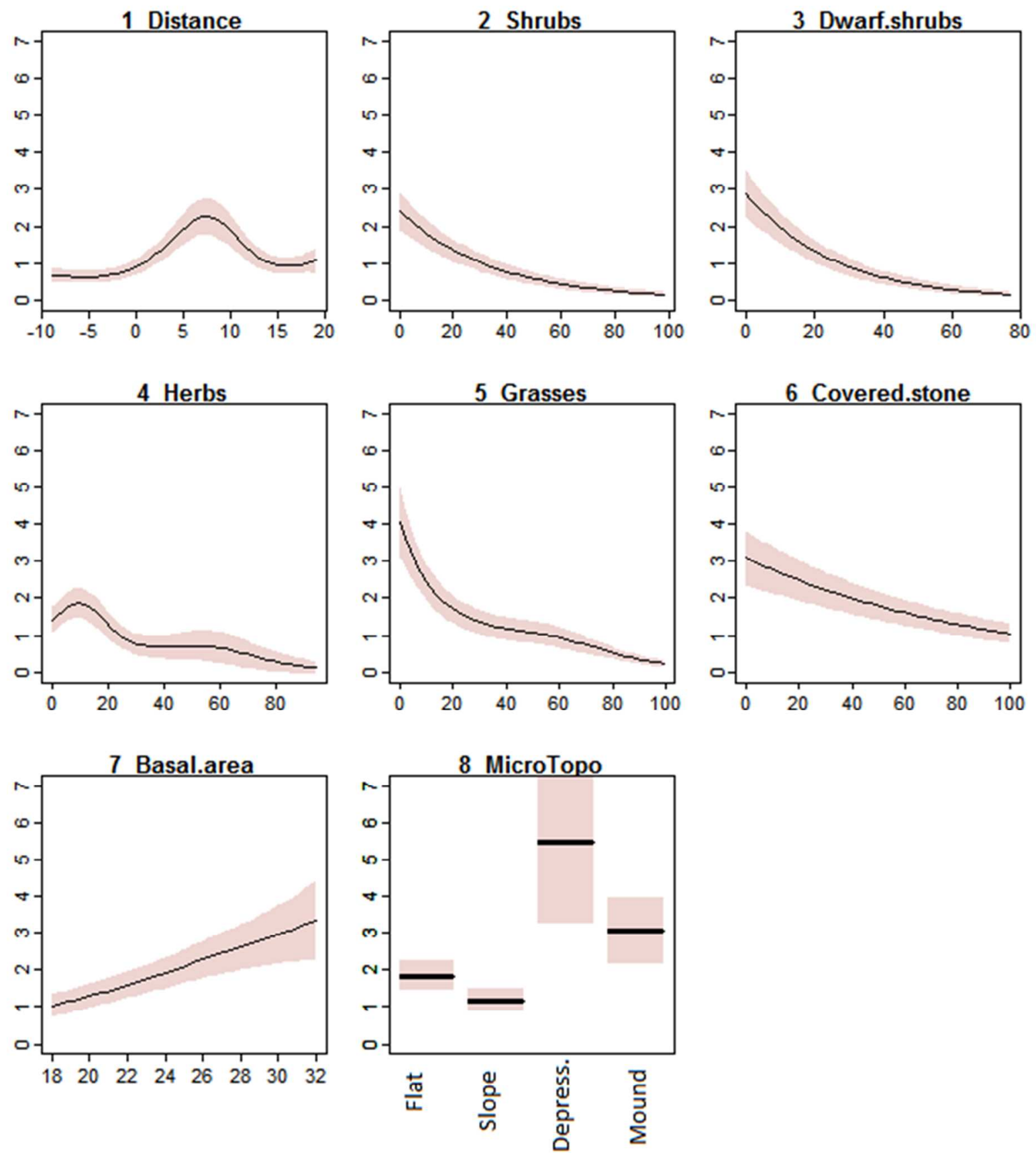

Figure 5. Estimated seedling density $\left(\right.$ per $\left.\mathrm{m}^{2}\right)$ for spruce which emerged after harvest as a function of GAM covariates, fixed for flat topography. Shaded bands indicate the $95 \%$ confidence intervals. Distance $=$ distance of plot $i$ from the gap edge $(\mathrm{m})$; Basal area $=$ basal area of the residual forest surrounding the gap of plot $i\left(\mathrm{~m}^{2}\right.$ ha $\left.{ }^{-1}\right)$; Shrubs, Dwarf shrubs, Herbs, Grasses = percent cover of each floristic group on plot $i(\%)$; and Covered stone $=$ percent cover of this microsite type on plot $i(\%)$. 
Fig. 6.
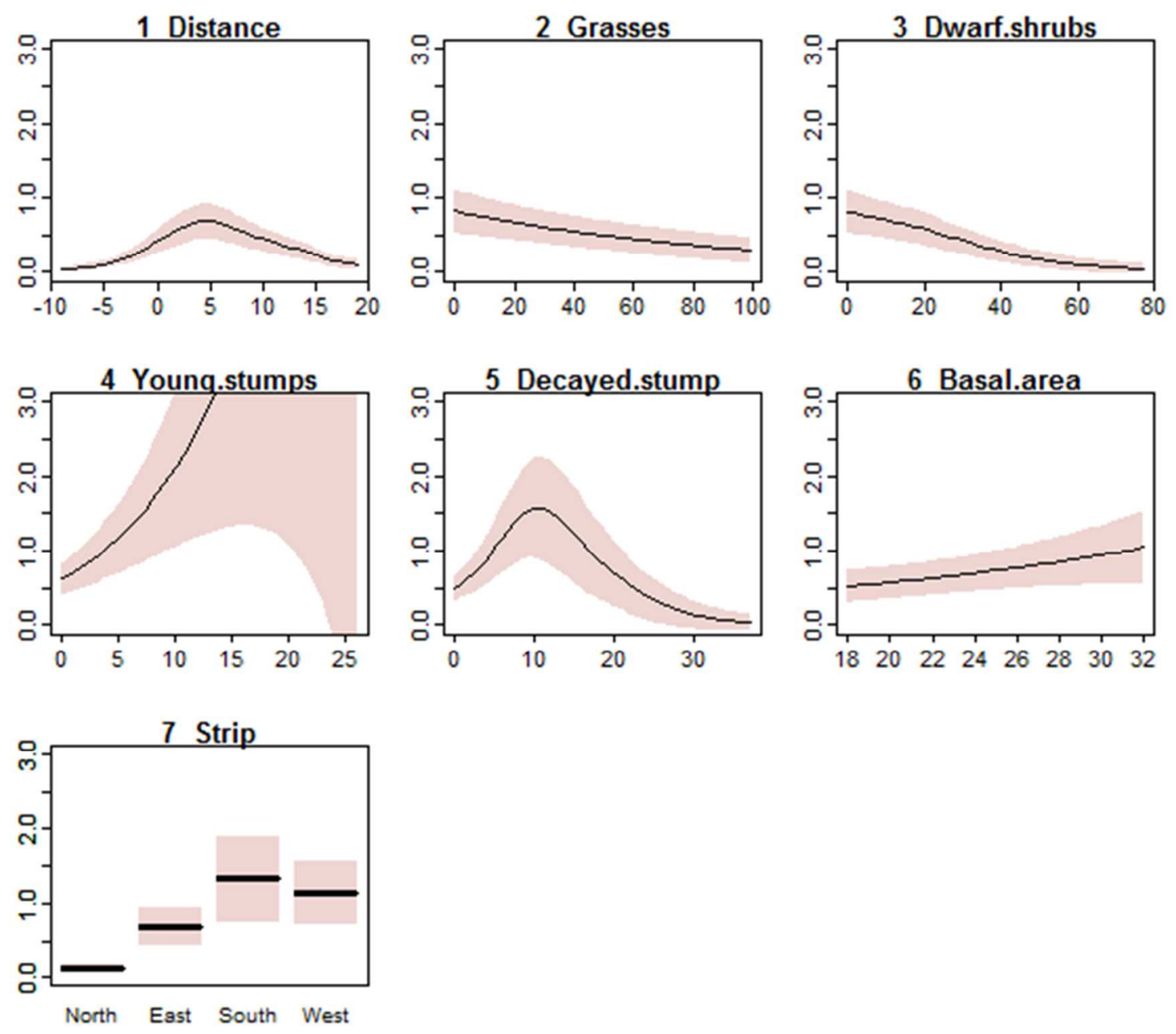

Figure 6. Estimated seedling density $\left(\right.$ per $\mathrm{m}^{2}$ ) for birch which emerged after harvest as a function of GAM covariates, fixed for an eastern strip orientation. Shaded bands indicate the $95 \%$ confidence intervals. Strip = orientation class of sampling strip of plot $i$ (North, South, East, West); and Young stumps, Decaying stumps = percent cover of these microsite types on plot $i(\%)$; others are as explained in Fig. 5 caption. 